\title{
ANAL YSIS OF STRUCTURAL BUILDING STRENGTH ASRAMA PUTRI ACEH BARAT WITH USE SEISMIC ISOLATION ON KOBE AND EL - CENTRO EARTHQUAKE
}

\author{
Andi Yusra ${ }^{1}$, Aulia Rahman' ${ }^{3}{ }^{3}$ Fizarya Musliadi \\ ${ }^{1,2,3)}$ Jurusan Teknik Sipil, Fakultas Teknik, Universitas Teuku Umar, \\ e-mail : yusra.andi@yahoo.com
}

\begin{abstract}
Abstrak
Perencanaan struktur bangunan di Indonesia harus dibuat dengan baik disebabkan karena sebagian besar wilayahnya memiliki tingkat kerawanan yang tinggi terhadap gempa. Salah satunya Provinsi Aceh yang berada pada daerah paling rawan gempa. Analisis dilakukan dengan tujuan mengevaluasi kinerja struktur terhadap perencanaan untuk menguji daya tahan sebuah gedung dengan cara menganalisis besarnya Displacement yang terjadi pada saat berlangsungnya gempa. Dengan menggunakan metode $3 D$ nonlinear earthquake response analysis (Respon Spektrum) kita dapat mengetahui besarnya tingkat resiko yang akan dialami oleh gedung tersebut. Spektrum respons dipakai untuk menentukan gaya horizontal maupun simpangan struktur MDOF. Spektrum respons disajikan dalam bentuk grafik/plot antara periode getar struktur T. Respon-respon maksimum dapat berupa simpangan maksimum (spektrum displacement, SD) kecepatan maksimum (spektrum velocity, SV) atau percepatan maksimum (spectrum accelaration, SA) massa struktur. Analisis menggunakan metode 3D nonlinear earthquake response analysis (Respon Spektrum) ini sangat baik dilakukan pada gedung-gedung yang akan dibangun atau gedung-gedung yang sudah lama dan sudah terkena dampak bencana gempa di kawasan-kawasan yang rawan gempa seperti di Aceh, agar didapat bangunan yang aman, kuat, kokoh, dan tahan terhadap gempa. Dalam analisis ini gedung yang akan dilakukan analisis terhadap strukturnya adalah gedung Asrama Putri Aceh Barat, Komplek Asrama IPELMABAR, Lamreung Banda Aceh. Gedung tersebut telah di lakukan penambahan seismic isolasion dan membandingkan dengan gedung tanpa seismic isolasion terhadap gempa kobe dan el centro. Analisisya dilakukan menggunakan aplikasi STERA 3D .Perangkat lunak ini dikembangkan untuk menganalisis struktur bangunan terhadap gempa. Hasil dari analisis tersebut bahwa seismic isolasion dapat meredam getaran gempa yang di berikan sehingga seismic isolasion merupakan salah satu solusi untuk perencanaan bangunan tahan gempa.
\end{abstract}

Kata Kunci : $\quad$ Metode 3D nonlinear earthquake response analysis.

\begin{abstract}
The structural design of buildings in Indonesia should be made well because most of the region has a high level of vulnerability to earthquakes. One of them is Aceh who are in the most vulnerable areas gempa.Analisis done with the aim of evaluating the performance of the structure of the plan to test the durability of a building by analyzing the amount of displacement that occurs at the time of the quake. By using 3D nonlinear earthquake response analysis (Respon Spektrum) we can determine the level of risk that will be experienced by the building tersebut.Spektrum responses were used to determine the horizontal force and deflection MDOF structure. Response spectrum is presented in the form of charts / plots between a vibration period T. structure responses can be a maximum of maximum deviation (displacement spectrum, SD) maximum speed (velocity spectrum, SV) or maximum acceleration (Acceleration spectrum, SA) using the mass struktur.Analisis methods of $3 D$ nonlinear earthquake response analysis (Respon Spektrum) is very well done to the buildings to be constructed or buildings is old and has been affected by the earthquake in areas that are prone to earthquakes such as in Aceh, in order to obtain a secure building, Strong, sturdy, and resistant to earthquakes. In this analysis of the building will be carried out an analysis of the structure is Asrama Putri Aceh Barat, dormitory complex IPELMABAR, Lamreung Banda Aceh. The building has been done adding seismic isolasion and compare with the building against earthquakes without seismic isolasion kobe and el centro.Analisis that do use software application 3D. STERA was developed to analyze the structure of the earthquake. Result of the analysis that can dampen the seismic isolasion tremor that is given so that the seismic isolasion is one solution for planning of earthquake resistant buildings.
\end{abstract}

Keywords: 3D nonlinear method of earthquake response analysis. 


\section{PENDAHULUAN}

Indonesia merupakan Negara strategis yang terletak diantara 3 lempeng tektonik yaitu lempeng indo- Austria, Eurasia dan Pasifik. Keberadaan Indonesia yang terletak diantara lempenglempeng aktif ini membuat Indonesia sangat rawan terhadap gempa, baik skala kecil mupun besar. Oleh karna itu perencanan tahan gempa merupakan hal yang sangat penting untuk mengantisipasi timbulnya korban jiwa.

Dalam analisis ini gedung yang akan dilakukan analisis terhadap strukturnya adalah gedung Asrama Putri Aceh Barat Komplek Asrama IPELMABAR, Lamreung Banda Aceh. Aplikasi yang di gunakan dalam analisis ini adalah STERA $3 D$ yang mana Perangkat lunak ini dikembangkan untuk menganalisis struktur bangunan terhadap gempa

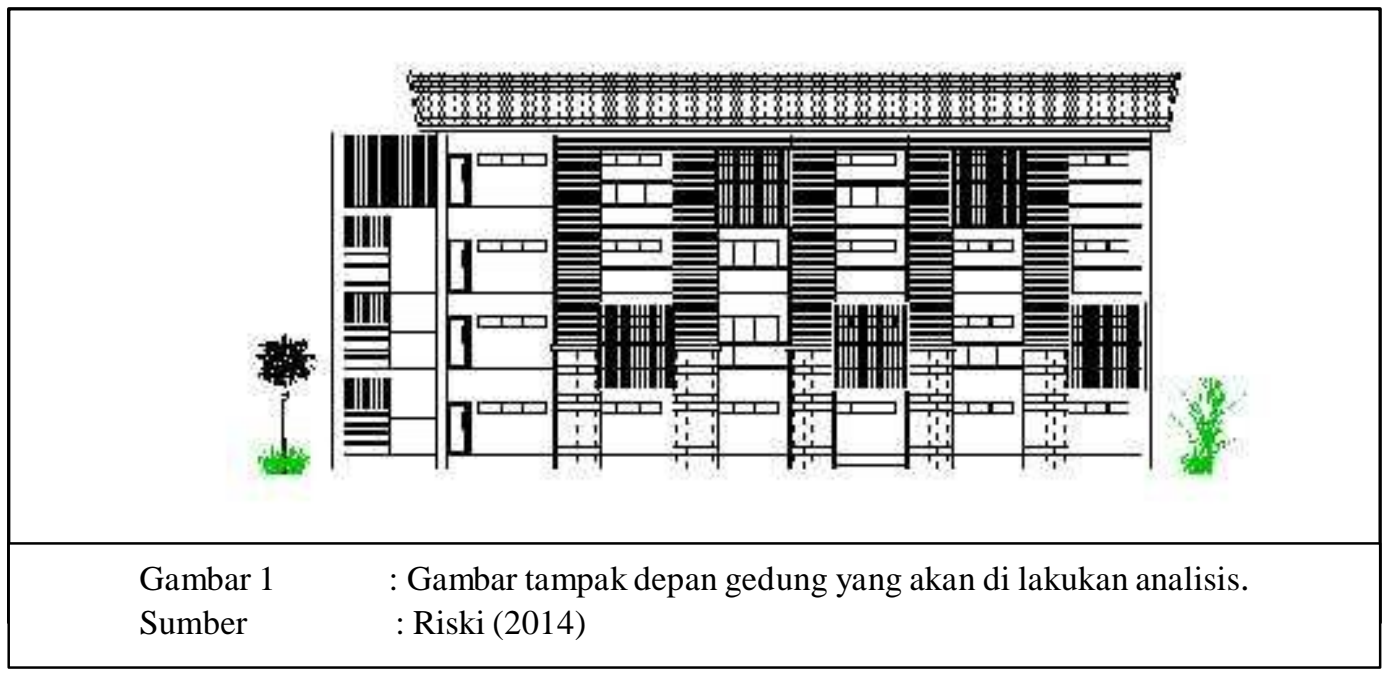

\section{Pengertian Gempa}

Gempa bumi adalah peristiwa bergetarnya bumi akibat pelepasan energi di dalam bumi secara tiba-tiba yang ditandai dengan patahnya lapisan batuan pada kerak bumi. Akumulasi energi penyebab terjadinya gempabumi dihasilkan dari pergerakan lempeng-lempeng tektonik. Energi yang dihasilkan dipancarkan kesegala arah berupa gelombang gempabumi sehingga efeknya dapat dirasakan sampai ke permukaan bumi.

\section{Tipe gempa bumi.}

Tipe-tipe gempa bumi dapat digolongkan menjadi:

- Gempa bumi vulkanik (Gunung Api).

Gempa bumi ini terjadi akibat adanya aktivitas magma, yang biasa terjadi sebelum gunung api meletus. Apabila keaktifannya semakin tinggi maka akan menyebabkan timbulnya ledakan yang juga akan menimbulkan terjadinya gempa bumi. Gempa bumi tersebut hanya terasa di sekitar gunung api tersebut.

- Gempa bumi tektonik.

Gempa bumi ini disebabkan oleh adanya aktivitas tektonik, yaitu pergeseran lempeng-lempeng tektonik secara mendadak yang mempunyai kekuatan dari yang sangat kecil hingga yang sangat besar. Gempabumi ini banyak menimbulkan kerusakan atau bencana alam di bumi, getaran gempa bumi yang kuat mampu menjalar keseluruh bagian bumi.

\section{Deskripsi Gempa El-Centro}


Gempa El-Centro yang terjadi di California Amerika Serikat adalah salah satu gempa terdahsyat dengan nilai magnitude 7,1 yang pernah terjadi di bumi ini dimana sekitar $80 \%$ bangunan yang ada dikota California bagian utara di jalan Imperial mengalami kerusakan yang sangat parah. Disepanjang jalan Brawley sebagai pusat bisnis kota, seluruh struktur bangunan nengalami kerusakan yang parah. Dampak getaran yang terjadi dirasakan sampai sekitar 40 mil disepanjang jalan Imperial. Kerugian yang diperkirakan pada saat itu adalah sekitar \$US 6 juta.

Peraturan UBC telah dibuat pada tahun 1994, dan direvisi ulang pada tahun 1997 setelah gempa dahsyat terjadi di kota Kobe, Jepang. Peraturan UBC juga merupakan peraturan yang dibuat berdasarkan peraturan ACI 318- 95. Perancangan gaya geser dasar minimum pada daerah Zona 4 menurut UBC juga dibuat berdasarkan hasil penelitian dan observasi gerakan tanah pada daerah sekitar pada saat terjadi di gempa Nortbridge, California pada tahun 1994.

\section{Deskripsi Gempa Kobe.}

Dhimas (2009) menjelaskan bahwa gempa bumi berkekuatan 7.2 di Kobe, Jepang, disebut sebagai bencana paling mahal sepanjang masa. Yang paling menakjubkan dari kekuatannya adalah bahwa gempa tahun 1995 ini telah menghancurkan dan menewaskan ribuan korban yang sama sekali tak menduganya, dalam waktu yang singkat dari awal hingga akhir, pada pukul 5.46 pagi hari gempa bumi terjadi selama dua puluh detik, dan dibutuhkan selama satu dekade untuk memulihkannya.

Di Kobe juga terdapat sebuah jalan tol yang rubuh, padahal menurut kontraktornya, jembatan ini mampu menahan gempa yang terjadi di Kobe. Tetapi pada kenyataannya jalan tersebut roboh ke samping. Setelah diteliti, ternyata tali baja yang seharusnya memanjang sampai pada tinggi tiang penyangga hanya separuh dari tinggi tiangnya, hasilnya adalah jembatan tersebut tidak kuat menopang guncangan gempa dan berakhir dengan roboh. Laporan $E Q E$ menyimpulkan hasil pemeriksaannya dalam kalimat berikut: "Gempa Kobe adalah contoh sangat mengerikan dari apa yang bisa diakibatkan oleh gempa bumi" .

\section{Aplikasi yang digunakan.}

Aplikasi yang penulis gunakan pada analisis ini adalah program STERA_3D dimana STERA_3D adalah perangkat lunak yang terintegrasi untuk analisis seismik bangunan beton bertulang dalam ruang tiga dimensi yang dikembangkan untuk tujuan Perencanaan dan pendidikan. STERA_3D memilik visualisasi untuk menciptakan model bangunan dan menunjukkan hasil dengan mudah dan cepat.

STERA_3D memungkinkan pengguna untuk melakukan analisis bangunan sebagai berikut:

a. 3 D elastic modal

analysis,

b. 3D nonlinear static push-over

analysis,

c. 3D nonlinear earthquake response

analysis,

Terdapat beberapa Pemodelan yang bisa dilakukan dalam aplikasi ini, akan tetapi pada analisis ini penulis hanya melakukan beberapa Pemodelan diantaranya ialah sebagai berikut: Balok (Beam), Kolom (Column), Dinding (Wall), Isolator.

\section{Seismic isolation}

Menurut Concise Oxford Dictionary, definisi seismic isolation(isolasi seismik) adalah bagian yang dapat memisahkan struktur atas dengan pondasi, atau bagian lain yang dapat memisahkan struktur atas dengan struktur bawah.Perbandingan antara bangunan tanpa seismic isolation (isolasi seismik) dan bangunan dengan 
seismic isolation (isolasi seismik) adalah sebagai berikut:

\section{METODE PENELITIAN}

\section{Sumber Data}

Data-data yang digunakan dalam analisis ini diambil berdasarkan data primer dan sekunder. Sistematika pengambilan data dimulai dari pengumpulan data dan pengolahan data.

\section{Pengumpulan Data}

Dalam tahapan ini penulis melakukan pengumpulan data primer dan data sekunder yang berupa kajian tentang pelaksanaan analisis, informasi tentang gedung, literatur dan deskripsi tentang gempa (dari pengertian gempa, faktor terjadinya, sampai dengan gempa yang datanya penulis gunakan dalam analisis ini), hal ini guna untuk memudahkan penulis dalam melakukan analisis.

\section{Tahapan Perencanaan}

Tahap perencanaaniniakan dimulai dengan tahapan-tahapan sebagai berikut:

1. Perhitungan Pembebanan bangunan.

2. Pengaturan Pola Elemen Struktur.

3. Memasukkan Informasi Elemen.

4. Analisis.

5. Pembacaan Hasil Analisis.

6. Pengambilan Kesimpulan.

\section{Perhitungan pembebanan bangunan.}

Terdapat beberapa tahapan yang dilakukan pada perhitungan pembebanan ini diantaranya, perhitungan pembebanan yang berupa beban mati dan beban hidup pada konstruksi atap, konstruksi lantai satu, lantai dua, lantai tiga, dan empat. Hal ini dilakukan untuk mengetahui besarnya beban yang ditanggung oleh suatu bangunan. Nantinya besaran beban yang di tamping oleh gedung ini akan di masukkan pada pengaturan pola element struktur sebelum melakukan analisis dengan menggunakan apliksi STERA 3D.

\section{Memasukkan informasi element.}

Dalam Tahapan ini dilakukan pemodelan dengan memasukkan data/ informasi dari element bangunan gedung diantaranya sloof, kolom, balok, dan dinding. Adapun informasi/ data yang di masuk kan dalam pemodelan ini berupa:

a. Dimensi sloof, jarak selimut beton, diameter tulangan, jumlah tulangan, jarak tulangan, berat jenis, mutu beton.

b. Dimensi kolom, jarak selimut beton, diameter tulangan, jumlah tulangan, jarak tulangan, berat jenis, mutu beton.

c. Dimensi balok, tebal plat lantai, jarak selimut beton, diameter tulangan, jumlah tulangan, jarak tulangan, berat jenis, mutu beton.

d. Dinding, lebar bata, tebal bata, tebal spaci.

e. Jenisisolator, tebal isolator dantinggi isolator. 


\section{Pembacaan hasil.}

Untuk pembacaan hasil, penulis masukkan data dari hasil analisis yang telah dilakukan dengan apliaksi STERA $3 D$ ke program microsoft excel untuk melakukan olah data sebelum analisis Perbandingan kekuatan struktur asrama putri aceh barat yang di tambahkan isolator terhadap gempa Kobe dan El - centro.Perbedaan yang terjadi akan terlihat jelas pada grafik perbandingan berdasarkan data analis yang telah dilakukan.

\section{HASIL DAN EMBAHASAN}

\section{Pembebanan Konstruksi}

Pembebanan ini mencakup pembebanan konstruksi atap dan lantai di lakukan perhitungan beban mati dan beban hidup yang selanjutnya pembebanan itu akan dikombinasikan menjadi berat total konstruksi. Hasil dari perhitungan pembebanan atap dapat di lihat di tabel 1, dan hasil perhitungan pembebanan lantai dapat di lihat di tabel 2 .

Tabel 1 Pembebanan atap

\begin{tabular}{|c|c|c|c|c|c|c|c|c|}
\hline \multirow[b]{2}{*}{ Titik buhul } & \multicolumn{4}{|c|}{ Beban Mati (Kg) } & \multicolumn{2}{|c|}{ Beban Hidup } & \multirow{2}{*}{$\begin{array}{c}\text { Jumlah } \\
\text { (kg) }\end{array}$} & \multirow{2}{*}{$\begin{array}{c}\text { Pembulatan } \\
\text { (kg) }\end{array}$} \\
\hline & $\begin{array}{c}\text { Berat } \\
\text { sendiri }\end{array}$ & $\begin{array}{l}\text { Berat atap } \\
\text { + Gording }\end{array}$ & $\begin{array}{c}\text { Berat } \\
\text { plafond + }\end{array}$ & $\begin{array}{c}\text { Ikatan } \\
\text { Angin } \\
(\mathbf{k g})\end{array}$ & $\begin{array}{l}\text { Huian } \\
(\mathrm{kg} / \mathrm{m})\end{array}$ & $\begin{array}{l}\text { Orang/ } \\
\text { Pekerja }\end{array}$ & & \\
\hline $\mathrm{A}$ & 5,970065 & 32,50917 & 12,96 & - & 28,512 & 100 & 179,9512 & 180 \\
\hline $\mathrm{B}$ & 5,970065 & 32,50917 & 12,96 & - & 28,512 & 100 & 179,9512 & 180 \\
\hline$\overline{\mathrm{C}}$ & 6,027332 & - & 25,92 & - & - & 100 & 131,9473 & 132 \\
\hline $\mathrm{D}$ & 7,77397 & - & 25,92 & - & - & 100 & 133,694 & 134 \\
\hline $\mathrm{E}$ & 7,77397 & - & 25,92 & - & - & 100 & 133,694 & 134 \\
\hline $\mathrm{F}$ & 6,027332 & - & 25,92 & - & - & 100 & 131,9473 & 132 \\
\hline $\mathrm{G}$ & 3,836876 & 19,88436 & - & - & 19,872 & 100 & 143,5932 & 144 \\
\hline $\mathrm{H}$ & 6,7718 & 24,94966 & - & - & 22,368 & 100 & 154,0895 & 155 \\
\hline I & 9,219957 & 31,26561 & - & - & 26,688 & 100 & 167,1736 & 168 \\
\hline $\mathrm{J}$ & 6,7718 & 24,94966 & - & - & 22,368 & 100 & 154,0895 & 155 \\
\hline $\bar{K}$ & 3,836876 & 19,88436 & - & - & 19,872 & 100 & \begin{tabular}{|l}
143,5932 \\
\end{tabular} & 144 \\
\hline $\mathrm{L}$ & 5,955748 & - & - & - & - & 100 & 105,9557 & 106 \\
\hline $\bar{M}$ & 5,955748 & - & - & - & - & 100 & 105,9557 & 106 \\
\hline & & & & & & & & 1870 \\
\hline
\end{tabular}

Tabel 2 Pembebanan lantai

\begin{tabular}{|c|c|c|c|}
\hline \multirow{2}{*}{ Lantai } & beban mati $(\mathrm{kg})$ & beban hidup $(\mathrm{kg})$ & W.total lantai $(\mathrm{kg})$ \\
\hline 4 & 317790.5 & 15045 & 332835.5 \\
\hline 3 & 274694.5 & 18495.6 & 293190.1 \\
\hline 2 & 269339.5 & 18375.6 & 287715.1 \\
\hline 1 & 263971 & 18375.6 & 282346.6 \\
\hline
\end{tabular}




\section{Kondisi fisik gedung sebelum dilakukan analisis respons spektrum.}

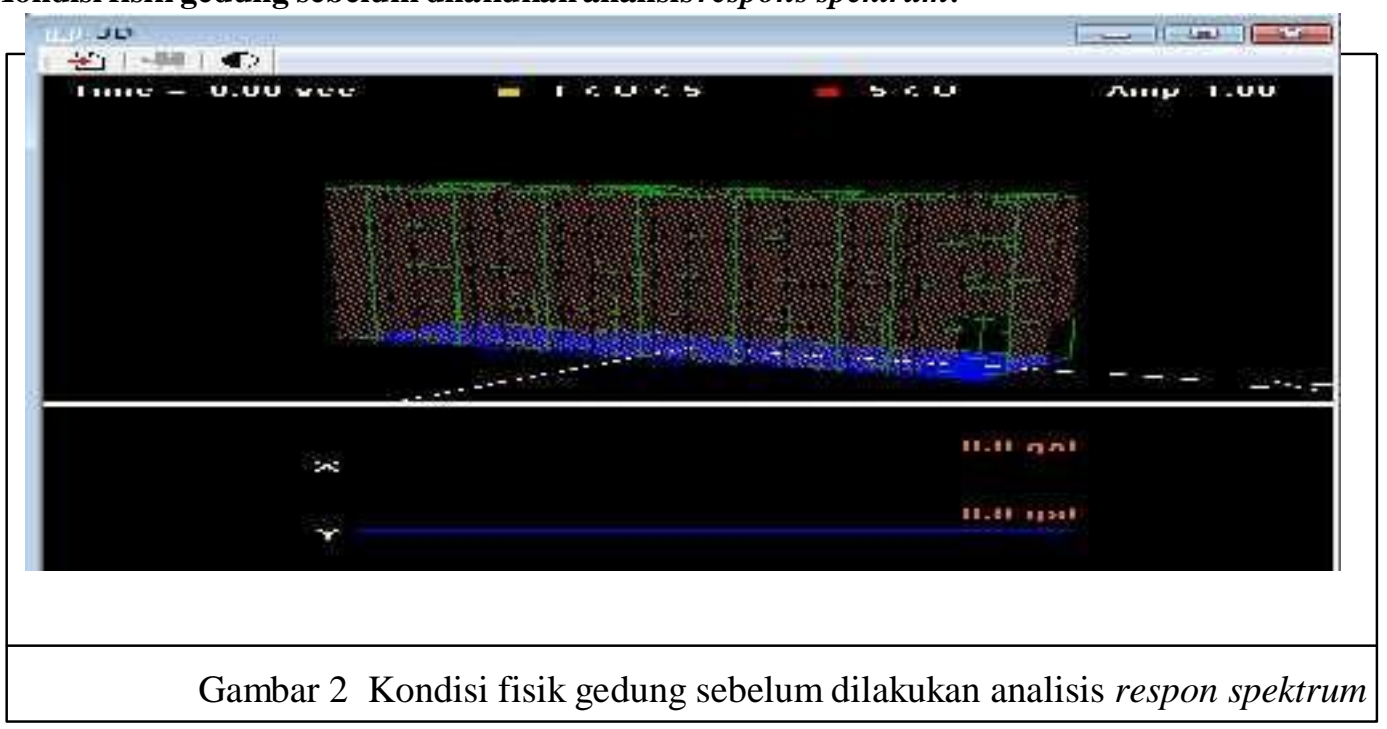

Ini adalah kondisi dimana gedung sebelum di lakukan analisis menggunakan stera $3 \mathrm{D}$, di mana $1<\mathrm{U}<5$ (kerusakan dari ringan sampai sedang) di tandai dengan warna kuning dan $5<\mathrm{U}$ (kerusakan sedang sampai parah) di tandai dengan warna merah dan Amp (gaya respon) analisis dengan menggunakan rekaman gempa kobe jepang yang berdurasi selama 20 detik dan El-centro yang berdurasi selama 15 detik.

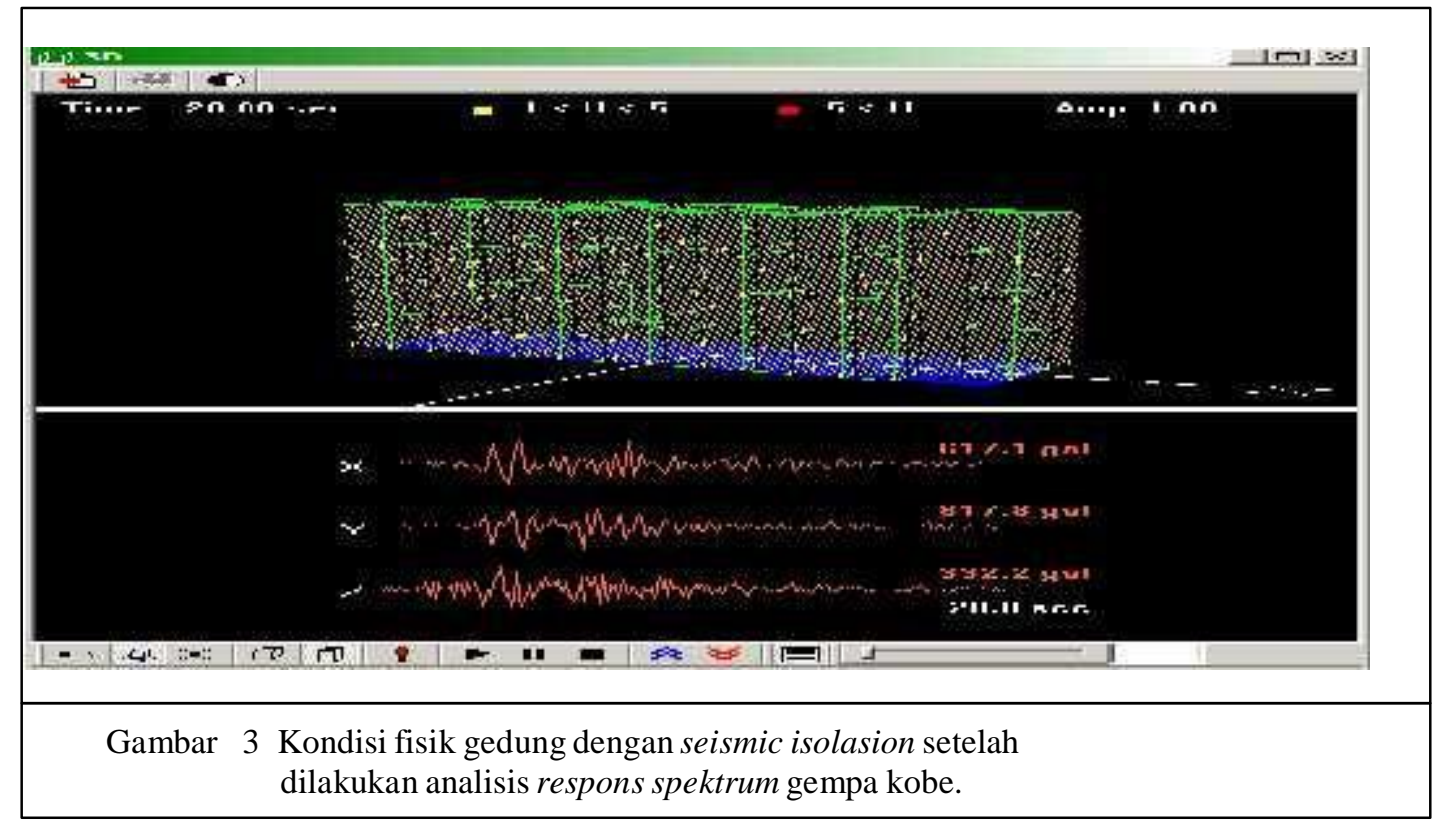

\section{Kondisi fisik gedung sesudah dilakukan analisis respon spektrum.}

Ini adalah kondisi dimana gedung dengan menggunakan seismic isolasion telah selesai dilakukan analisis dengan menggunakan rekaman gempa Kobe yang berdurasi selama 20 detik, dimana hampir semua titik mengalami kerusakan dari ringan sampai sedang. 


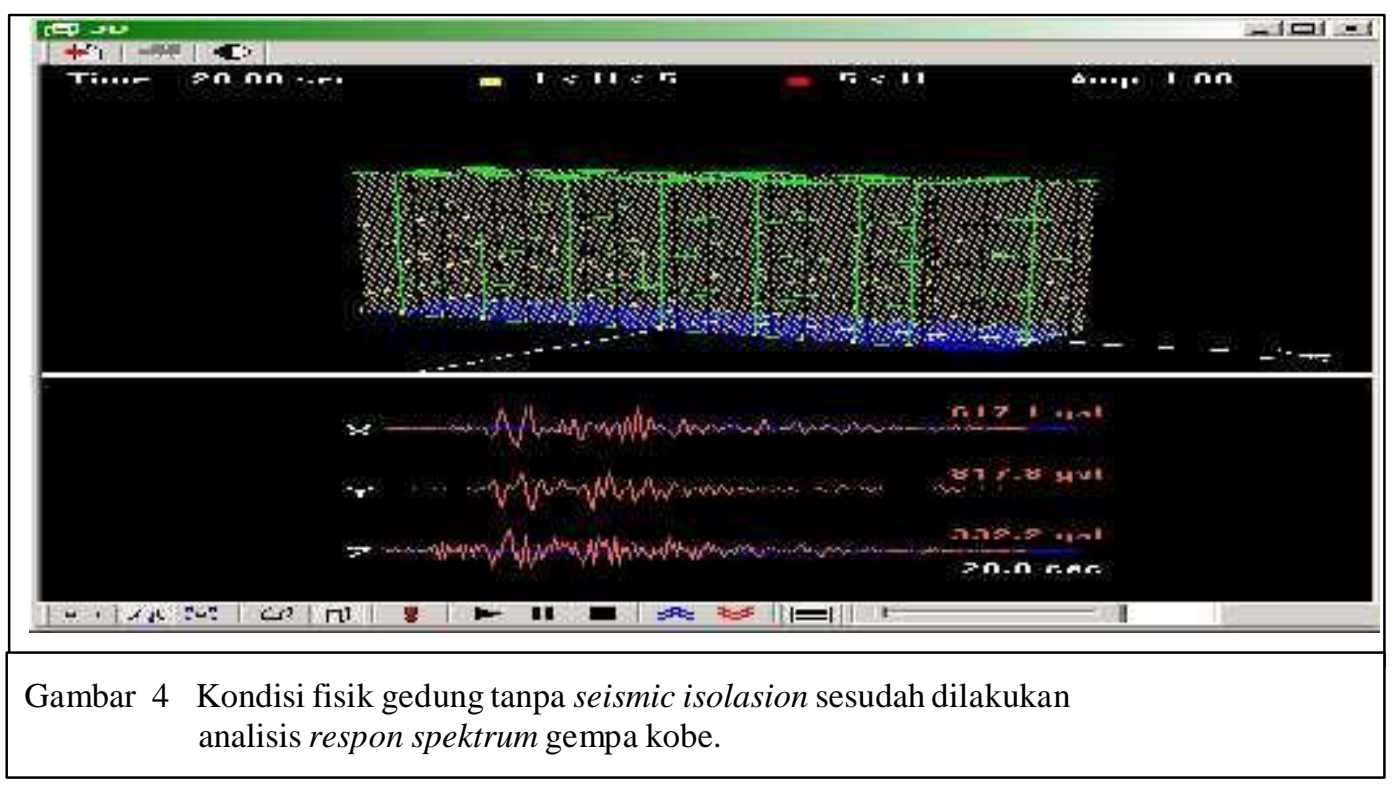

kondisi dimana gedungtanpa menggunakan seismic isolasion telah selesai dilakukan analisis dengan menggunakan rekaman gempaKobe yang berdurasi selama 20 detik, dimana hampir semua titik dari mengalami kerusakan dari ringan sampai sedang dan ada titik yang mengalami kerusakan sedang sampai parah.

\section{KESIMPULAN DAN SARAN}

\section{Kesimpulan}

Setelah melakukan analisis menggunakan metode respon spektrum pada bab 4, maka penulis dapat mengambil kesimpulan sebagai berikut:

1. Saran : 1.Berdasarkan analisis ragam sprectum respon pada arah $\mathrm{X}$ dan $\mathrm{Y}$ menghasilkan $\mathrm{Vi} \geq 0.85 \mathrm{~V}$, maka dapat di simpulkan bahwa nilai akhir respon dinamik struktur gedung yang menggunakan seismic isolasion maupun yang tidak menggunakan seismic isolasion terhadap pembebanan gempa nominal akibat pengaruh gempa Kobe dan El-centro telah memenuhi syarat SNI 03-1726-2012 pasal 7.9.4.1

2. 2.Berdasar evaluasi kinerja menurut ATC-40 level kinerja gedung Gedung Asrama Putri Aceh Barat dengan seismic isoalsion dan tanpa seismic isolasion dengan beban kobe tergolong pada Damage Control.

3. 3.Sedangkan gedung GedungAsrama Putri Aceh Barat dengan seismic isoalsion dan tanpa seismicisolasion dengan beban $\mathrm{El}$ - centro tergolong pada Immeddiate Occupancy

Sạan 1.Berdasarkan analisis ragam sprectum respon pada arah $\mathrm{X}$ dan $\mathrm{Y}$ menghasilkan $\mathrm{Vi} \geq 0.85 \mathrm{~V}$, maka dapat di simpulkan bahwa nilai akhir respon dinamik struktur gedung yang menggunakan seismic isolasion maupun yang tidak menggunakan seismic isolasion terhadap pembebanan gempa nominal akibat pengaruh gempa Kobe dan El-centro telah memenuhi syarat SNI 03-1726-2012 pasal 7.9.4.1

5. 2.Berdasar evaluasi kinerja menurut ATC-40 level kinerja gedung Gedung Asrama Putri Aceh Barat dengan seismic isoalsion dan tanpa seismic isolasion dengan beban kobe tergolong pada Damage Control.

6. 3.Sedangkan gedung GedungAsrama Putri Aceh Barat dengan seismic isoalsion dan tanpa seismic

7. isolasion dengan beban $\mathrm{El}$ - centro tergolong pada Immeddiate Occupancy 
1. Diharapkan setiap gedung yang akan dibangun atau gedung-gedung yang sudah lama dan sudah terkena dampak gempa di kawasan-kawasan yang rawan gempa seperti di Aceh, nantinya juga dilakukan analisis terhadap struktur bangunannya untuk mendalami perilaku seismik gedung agar didapat bangunan yang aman,kuat, kokoh, dan tahan terhadap gempa.

2. Diharapkan juga nantinya analisis dengan metode Respons Spektrum ini bisa terus dikembangkan lagi oleh mahasiswa yang lain untuk lebih mendalami perilaku seismik pada gedung.

\section{DAFTAR PUSTAKA}

Budi, A., 2011,Evaluasi kinerja seismic struktur beton dengan analisis pushover prosedur A dengan menggunakan program ETABS v 9.50. Universitas Sebelas Maret.

Clough, R.W.,and Penzien,J.,1975,DynamicsofStructures, McGraw-Hill,Inc.NewYork.

Kelly., 2001.Pengaruh penggunaan seismic base isolation system terhadap respons struktur gedung

Hotel Ibis Padang. Hlm. 46

Nurdianti, U., 2013, Studi keandalan struktur gedung tinggi tidak beraturan menggunakan pushover analisis pada tanah medium. Universitas Hasanuddin

Purnomo, E.,2014, Analisiskinerjastrukturpadagedungbertingkatdengananalisisdinamikresponsprektummengg unaka $n$ software ETABS v 9.50 (Studikasus: Bangunan hotel di semarang)Universitas Sebelas Maret.

Pranata, Y.A., 2006, Evaluasi Kinerja Gedung Beton Bertulang Tahan Gempa Dengan Pushover Analisys (Sesuai ATC-40, FEMA 356, dan FEMA 440), Jurnal Teknik Sipil, vol.3, no.1, pp. $41-$ 52.

Pranata, Y. A., 2008, Kajian daktalitas struktur gedung beton bertulang dengan analisis riwayat waktu dan analisis beban doroong.Jurnal Teknik Sipil, vol.8, no.3, pp. 250 - 263.

Riski, A.D.D., 2014, Analisis Kinerja Struktur Gedung Asrama Putri Aceh Barat Terhadap $\underline{\text { Gempa }}$ Kobe. Universitas Teuku Umar.

SNI03-1726-2002.TataCaraPerencanaanKetahananGempauntuk BangunanGedungdan Non

Gedung. Bandung2002.

SNI1726-2012.TataCaraPerencanaanKetahananGempauntuk BangunanGedung dan Non Gedung. Bandung2012.

Saito, T.,2011, STERA_3D Technical Manual Ver. 3.2, Building Research Institute, Japan.

Yoshioka, H., Ramallo, J.C., Spencer, B.F. "Smart" base isolation strategies employing magnetorheological dampers. Journal of Engineering Mechanics, May 2002. Hlm. 